\title{
Development of Optics Learning Model to Build Mental Models and Problem Solving Ability
}

\author{
Kartini Herlina ${ }^{1)}$ \\ Study Program of Physics Education \\ Lampung University \\ Bandar Lampung-Indonesia \\ el_qolibry2@yahoo.co.id
}

\author{
Mohamad Nur \\ Science Education-Graduate Programs \\ Surabaya State University \\ Surabaya-Indonesia
}

\author{
Wahono Widodo \\ Science Education-Graduate Programs \\ Surabaya State University \\ Surabaya-Indonesia
}

\begin{abstract}
One of the goals of physics instruction should be to enable the students to solve problems in a flexibly way. This requires the students to consider and to use multirepresentations as a natural part of the way they solve problems. This paper presents the results of our research on the development of optics learning model that was designed for the purpose of building mental models and problem solving ability, especially in the topic of light refraction. The learning model is called "ExPRession" model, developed based on one model of PBL namely the Illinois Mathematics and Science Academy (IMSA) model. Furthermore, we integrated the Polya's and Heller \& Heller problem solving strategies to IMSA PBL. We implemented our model in a limited test that conducted to 16 students of the 5th semester in physics education at Lampung University who were enrolled in an optics course. The learning model was implemented in three topics such as rectilinear propagation of light, refraction of light on a flat surface, and refraction of light on a curved surface. The results showed that "ExPRression" learning models could be categorized as "valid in contents" and as "valid in constructions", categorized as "practical", and categorized as "effective". The developed learning tools can be classified as a valid and could be used to support the implementation of the "Expression" learning model. The results in limited test showed that "ExPRression" learning model was effective in building mental model and improving aspects of problem solving ability.
\end{abstract}

Keywords-“ExPRession”model; problem solving ability; mental model,

\section{INTRODUCTION}

Problem solving is considered as an essential part of learning physics [1,2]. Thus the learning physics linked to develop problem solving ability. Problem solving is the process adopted by individuals to answer appropriately the problem, that find quantity of unknown variables as requested in the problem statement. Problem solving is used to stimulate a learning; includes the integration concepts and skills to overcame the unusual complex situations; and measuring of conceptual understanding. In physics teaching, the concept is illustrated with some representation from words to equations, graphs, and diagrams. Students who experience any difficulties, not only in creating these representations, but also how they revealed information and how they linked to each other. Some of them have difficulties when learning concepts and solving the problem.

Researches on problem solving on the topic of optical geometry found that students have difficulties to describe light diagrams on a mirror and a convex lens. Most of the students could not apply the principles of refraction to explain the real-world situations, even though they have been studying simple geometric optics. They often misunderstood the course of the rays of light according to the principle of refraction [5-10].

Our observations in the Physics Education Program at the Lampung University and Department of Physics at Surabaya State University, found that the pattern of lecturer teaching generally; 1) explaining the concepts, 2) giving the examples of problems in text book, 3) giving home works that to be collected next week. Problem solving ability was measured only by a final exam, and 4) not connecting their topics to the daily life or phenomena. Lecturer are rarely guiding how students create and use representations such as verbal, mathematical, graphical, and pictorial on solving the problems. In addition, a feedback of 40 students noted that lecturers teaching methods do not vary and not adapted to the characteristics of the material being discuss. Overall, our preliminary studies found that physics learning is not able to facilitate the strategy in solving problems.

Based on our observation, the feedback from the students, and research found that problem solving ability is related on 
the concept of light refraction. Students have difficulties on creating and using such representation (verbal, diagrams, mathematical, and pictorial) in solving the problem, therefore we need to develop a model of optics learning that helps the students in possessing sufficient problem solving abilities. According to Ausubel's learning theory, problem solving is a special case of meaningful learning. Therefore, any instructional system aimed at enhancing problem solving abilities should be designed in such a way as to promote meaningful learning. Achieving meaningful learning begins with building of correct, appropriate mental models, or representations, of the knowledge being acquired. Learning will be meaningful only if it can connect concepts that already exist within a person's cognitive structure [11].

To design an instructional we consider five learning stages (presented in Figure 1), namely: problems, activation, demonstration, application, and integration [12].

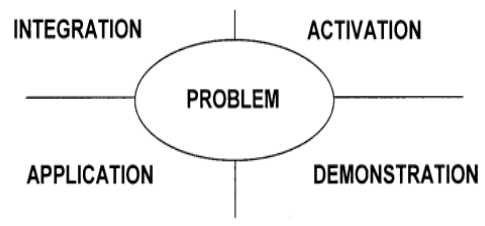

Fig. 1. Learning stages according for design an instructional

Problem centered, meaning that instructional conducted in order to solve the day to day problem/real world. The illstructured problem "serves as an initial stimulus and framework for learning. The students must learn to be conscious of what information they already know about the problem, what information they need to know to solve the problem, and the strategies to use to solve the problems.

Group work is an essential aspect of PBL, because group work helps to develop learning communities in which students feel comfortable in developing new ideas and raising questions about the material [13]. Groups do not always work effectively without guidance, they usually need the instructor to facilitate and monitors group interactions $[14,15]$. The instructors also need to find the appropriate balance between allowing students to discuss the issues on their own and intervening in group interactions.

\section{RESEARCH METHOD}

This study is a research development that focused on developing a model to help the students to build their mental models and problem solving ability on light refraction. This model was developed through several stages such as: early stage, development stage, and validation of the model.

The development of a model consist of 1) literature review, 2) preliminary studies to see the problem solving ability, 3) observation on physics course, and 4) giving a questionnaire to the lecturers and students. The questionnaire is to capture their perceptions of models, strategies, and approaches used in learning. In the literature review we consider the learning theories, the theories of PBL, the theories of mental models, and the theory of problem solving. Also the study findings related to the implementation of PBL on learning in higher education, student responses to the learning through PBL, problem solving ability in geometry optics, and researches on mental models and mental models theories.

We developed an optics learning model based on one model of PBL namely Illinois Mathematics and Science Academy (IMSA) model. Furthermore, we integrated the Polya's and Heller \& Heller problem solving strategies to IMSA PBL. Both problem solving strategies are depicted broadly only in focus on the problem steps and described the physics steps (shown in Figure 2). Indicators on the "focus on the problem" steps are to represent the problem on visualizing or sketching a picture and the indicators on the "describe the physics" steps is to create an external representation, for example a diagram that related to the problem.

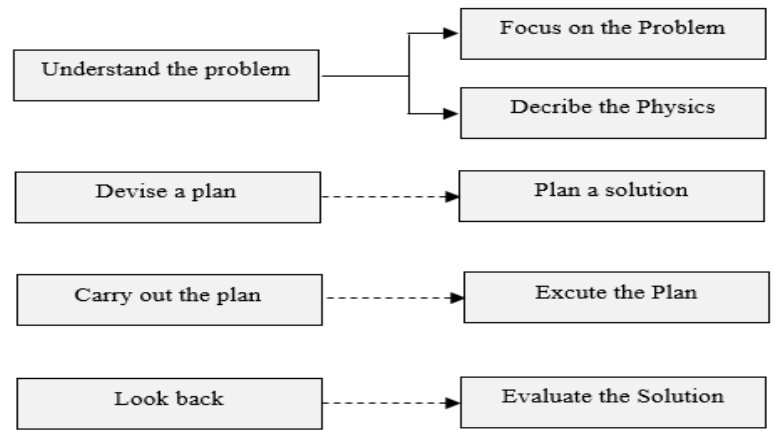

Fig. 2. Problem solving strategy: Polya and Heller \& Heller

One of the key features and conceptual basis of PBL are: using of 'problems' (these are called 'ill-structured) to stimulate [16]. The main components of the ill-structured problems solution are include the ability to create a representation of the problem and the ability to develop a solutions [15\}. In our model we feature the problem in form of images of a phenomenon including the topic being discussed as ill-structured problem. An example of the problem we displayed is a simple phenomena related to the light propagation in straight line concept. This concept was discussed before studying the light refraction that the students understood factors that contributed to the refraction of light. Our model starts by showing an image of phenomena to be observed (shown in Figure 4).

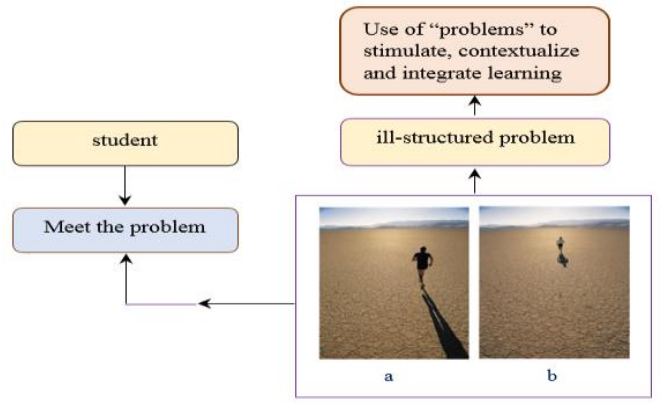

Fig. 3. Integration of phenomena for the student "Meet the problem" steps

We named the first step in our model as "meet the problem." Based on the phenomena, they identified the main problems to be investigated. Example of the problem related 
to the phenomena displayed in figure 4 such as: Compare the two pictures above. "Do you think these two people are running at the same time of day? How do you know? Make your prediction and explain your thinking." Students identify learning issues pertinent to the problems and ask questions related to these issues. They make their own decisions about in what directions to their investigations, what information to gather, and how to analyze and evaluate this information.

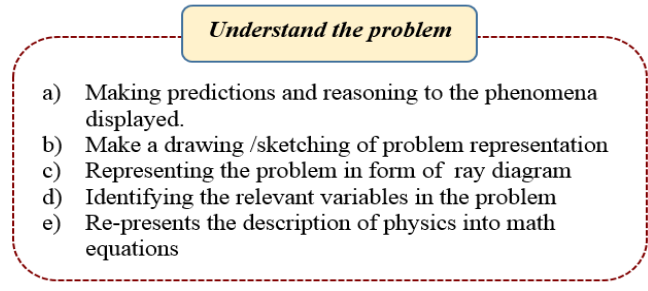

Fig. 4. Students activities in the "understand the problems" steps

The second step is named as the "understand the problem." Mental models in "ExPRession" learning model was started in "understand the problem" step through activities shown below. The next step is called as "problem solution." The problem is solved through experiment and numerically (students used such as: useful description, physics approach, specific application of physic, mathematical procedures, and logical progression. The last step of our model is known as "presenting the results"

\section{A. Validity}

In developing a learning models it is necessary to fullfiled three criteria, namely: validity, practically and effectiveness. [17]. The objective of content validity is to see the quality of learning models being developed and validated by five experts in the area of Science Education. A learning model has five basic elements, namely: 1) syntax, (2) social system, (3) principles of reaction, (4) support, and (5) instructional and nurturing effects [18].

\section{B. Testing the model}

The purpose of model testing is to determine the increase of ability in problem solving after being involved in "ExPRession" learning model. This study reported the results of limited test conducted to 16 students of the 5th semester in physics education at Lampung University who were enrolled in an optics course. Problem solving ability on written solution was assessed using rubrics adapted from Docktor [19].

Data were collected through three semi-structured interview protocols that designed to obtain student's mental model of light refraction. The first interview protocol was aimed to determine their understanding of the refraction of light, and some concepts in the light waves. Student's responses to this question were expected to provide a foundation and frame of reference to interpret their mental models. The second interview protocol was an interview about event that was designed to investigate the predictions and student's mental model on the light refraction. The third interview was to investigate student's reflection on their responses to the first and second interview.

\section{RESULTS AND DISCUSSION}

\section{A. Results}

In "ExPRession" learning model, the problems were solved by investigation and numerical. The steps consist of 1) meet the problem, 2) understanding the problem, 3) plan solution, 4) problem solution (through an experiment and numerical), 5) presenting the results.

After development the learning model, we conducted subsequently a Focused Group Discussion (FGD) that aimed to obtain more independent inputs and revisions. Furthermore the learning model was validated by five experts on Science Education. The validation results are shown in Table 1. Furthermore, the model was implemented on a small group of test that focused to see the effectiveness and practicality of the product. The effectiveness of the products is the level of applicability of the products developed on problem solving ability and the building mental models. Practicality of the product was viewed from the level of implementation learning model and student's activities in learning that was observed by two lecturers. As mentioned before, the learning model was implemented in three topic of learning such; rectilinear propagation of light, refraction of light on a flat surface, and refraction of light on a curved surface. Each topic was highlighted during two sessions consisted of $2 \times 50$ minutes plus 2 x 60 minutes. Implementation of learning in each topic was observed by two colleague lecturers. Before the implementation of the learning model, the students followed a series of pretest that gradually includes problem solving ability related to science process skills, work on problems associated with all three topics, and explore the students mental models concerning the light refraction. The average of values on learning observation is presented in Table II.

TABLE I. THE RESULTS OF MODEL VALIDATION AND LEARNING TOOLS

\begin{tabular}{|c|l|c|c|}
\hline No. & \multicolumn{1}{|c|}{ Component } & Mean & Criteria \\
\hline A & Learning model & 3.63 & VG \\
\hline B & Lesson plan & 3.50 & G \\
\hline C & Students worksheet & 3.58 & G \\
\hline C & Learning material & 3.50 & G \\
\hline D & Evaluation sheet & 3.56 & G \\
\hline E & Assessment sheet & 3.57 & G \\
\hline \multicolumn{2}{|l|}{ Total mean } & 3.53 & G \\
\hline Conclusion: The quality of the learning models learning tools categorize \\
as "G: Good" by a bit of revision.
\end{tabular}

The percentage of student activities in learning is shown in Figure 5 below. It is known that the student activities in the aspects of "discussing, questioning, and expressing to the opinions" during the application of "ExPRession" learning model dominates the entire learning activity, namely $15.20 \%$. 
TABLE II. OBSERVATION ON IMPLEMENTATION OF LEARNING MODEL

\begin{tabular}{|c|l|c|c|c|c|}
\hline \multirow{2}{*}{ No. } & \multirow{2}{*}{ Aspects } & \multicolumn{2}{c|}{ Observer } & \multirow{2}{*}{ mean } & \multirow{2}{*}{ criteria } \\
\cline { 3 - 4 } & & $\mathbf{1}$ & $\mathbf{2}$ & & \\
\hline A & Preparation activity & 3.75 & 3.50 & 3.63 & VG \\
\hline B & Core activity & & & & \\
\hline & Meeting the problem & 3.42 & 3.54 & 3.48 & G \\
\hline & $\begin{array}{l}\text { Understanding the } \\
\text { problem }\end{array}$ & 3.50 & 3.67 & 3.59 & VG \\
\hline & Planning solution & 3.63 & 3.58 & 3.61 & VG \\
\hline & Problem solution & 3.63 & 3.67 & 3.65 & VG \\
\hline & Presenting the results & 3.71 & 3.67 & 3.69 & VG \\
\hline C & Closing activity & 3.50 & 3.50 & 3.50 & G \\
\hline D & Atmosphere of class & 3.67 & 3.67 & 3.67 & VG \\
\hline E & Time management & 3.50 & 3.33 & 3.42 & G \\
\hline & \multicolumn{2}{|c}{ Total mean } & 3.57 & VG \\
\hline Connnnn
\end{tabular}

Conclusion:The implementation of learning model is categorized as "VG: Very Good" and running well.

The ability in problem solving was assessed based on the written solution of the problems and the values analyzed using N-Gain scores. Each student solve 5 problems from a physics textbook, one of the problems is as follows.

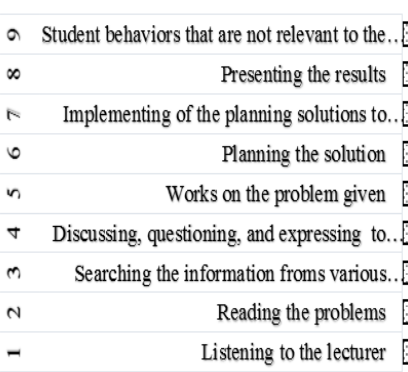

Fig. 5. Graph the percentage of students activities in learning

"After a long day of driving you take a late-night swim in a motel swimming pool. When you go to your room, you realize that you have lost your room key in the pool. You borrow a powerful flashlight and walk around the pool, shining the light into it. The light shines on the key, which is lying on the bottom of the pool, when the flashlight is held $1.2 \mathrm{~m}$ above the water surface and is directed at the surface a horizontal distance of $1.5 \mathrm{~m}$ from the edge. If the water here is $4.0 \mathrm{~m}$ deep, how far is the key from the edge of the pool?". An example of students solution can be seen in the Fig.6.

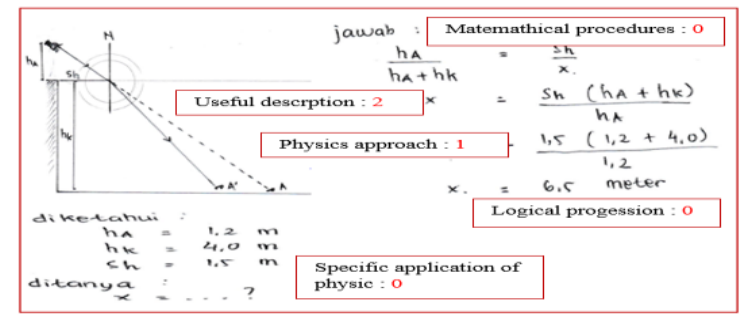

Each student completes five problem related to the topic of light refraction on flat and on curved surfaces. Students' ability to solve the problems are assessed based on the rubric adapted from Docktor [18]. As an example of student's solution can be seen in Figure 8. The solutions of the fifth problem were grouped into each descriptions: a) useful description, b) physics approach, c) specific application of physics, d) mathematical procedures, and e) logical progression. The average percentages of student in each description are shown in Table III.

TABLE III. PROBLEM SOLVING ABILITY

\begin{tabular}{|c|r|r|r|r|r|}
\hline \multirow{2}{*}{ Score } & \multicolumn{5}{|c|}{ Percentage of each aspect of problem solving ability } \\
\cline { 2 - 6 } & \multicolumn{1}{|c|}{$\mathbf{a}$} & \multicolumn{1}{c|}{ b } & \multicolumn{1}{c|}{$\mathbf{c}$} & \multicolumn{1}{c|}{ d } & \multicolumn{1}{c|}{ e } \\
\hline 5 & 40.00 & 36.77 & 35.48 & 35.48 & 34.84 \\
\hline 4 & 20.65 & 18.06 & 17.42 & 16.13 & 16.13 \\
\hline 3 & 18.06 & 14.19 & 11.61 & 13.55 & 12.90 \\
\hline 2 & 6.45 & 7.74 & 7.74 & 6.45 & 7.74 \\
\hline 1 & 5.16 & 4.52 & 7.10 & 8.39 & 8.39 \\
\hline 0 & 9.68 & 18.71 & 20.65 & 20.00 & 20.00 \\
\hline total & 100.00 & 100.00 & 100.00 & 100.00 & 100.00 \\
\hline
\end{tabular}

In Table III it appear that almost $60 \%$ of students in pre test did not use a useful description correctly, thus the students' ability to make representations of the problem was categorized low. Most of students did not write the symbols that have been generally conceived.

\section{B. Discussion}

Learning model developed is analyzed through an FGD forum, also be validated by five experts in the field of Education Science. The results of validation and observation on the implementation are tabulated in Table I and Table II. It summarized that the "ExPRession" learning model can be applied in teaching. The results of validation and revision on "ExPRession" learning model show that the model developed was feasible to be implemented in learning on light refraction topic. The "ExPRession" learning model was expected to provide a variety of learning model that can assist in overcoming any difficulties on learning refraction of light. So it could familiarize the students to have a high-order thinking skills. In addition, students were conditioned to build mental models and problem solving ability.

Based on Figure 6. it is known that the activities done by the students on the aspect of "discussing, questioning, and expressing to the opinions" during the application of "ExPRession" learning model dominates the entire learning activity, namely $15.20 \%$. Based on the data observed it is also known that there are irrelevant activities appearing in each aspect. Accordingly, in future studies it is needed to provide guidance in focusing students activities. The activity of problem solving involved in any stages of the models developed. It can be proved that "ExPRession" learning model could be one of the solutions in overcoming difficulties such as: 1) familiarizing the learning that can represent an abstract into concrete knowledge using various representations, 2) creating a student-centered learning, 3) providing a space for hypotheses testing activities to solve problems, and 4) providing flexibility for seeking the information from various sources.

Fig. 6. An example of students solution 
Figure 7 showed that a student did not describe all of the information in the problem completely and correctly (useful description: 2). He did not describe correctly the angle of incident ray and refraction ray in correspond with the problem statement. He did not consider the refractive index of each medium (physics approach: 1). He did not apply the Snell's law for refraction (specific application of physics: 0 ). They did not use formula that appears in a specific application of physics (mathematical procedures: 0), and the solutions are not logically connected (logical progression: 0 ). Overall, these student did not use problem representation, instead he solved the problem mechanically, and not using the concepts and principles on refraction, and he was not able to use the external representation.

In Table III, most of students did not write the symbols that have been generally conceived. Therefore the students would have mistake to interpret the angle of incident ray and refraction ray. The students assumed that the incident ray always comes from the viewer's eye. The mis-understanding on the incident ray will have an impact on the misapplication of Snell's law (Specific Application of Physics). The fault in defining the angle of incident and angle of refraction ray will cause errors in the mathematical procedure. The next logical progression experience will be inconsistent to statement of the problem.

After the engagement in "ExPRession" learning model, almost $80 \%$ of students solve the problems with a useful description correctly. Useful description is as a first step in improving students' understanding of the problem. They are required to identify the known variables, unknown variables, objects and the associated physics topic or domain in the problem statement. An aspect of useful description tends to affect other aspects. A low score on this aspect will also cause the scores on other aspects be low. In Figure 9. it appears that all the indicators of problem solving ability increased.

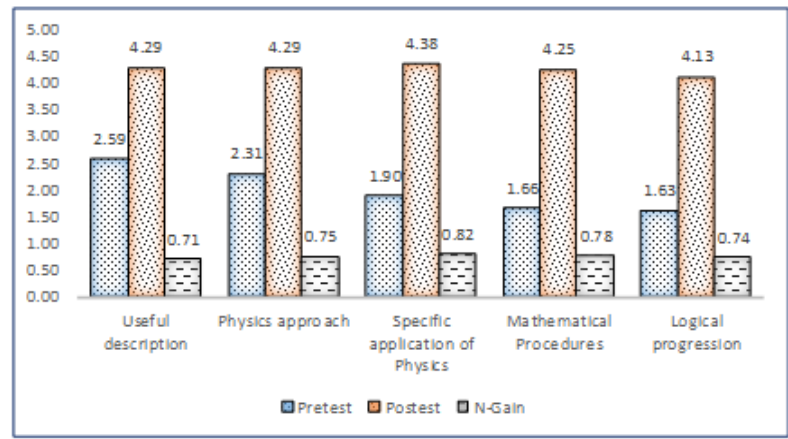

Fig. 7. Graph of increasing the problem solving ability on each indicator

Thus we stated that the "ExPRession" learning model as an effective mean in enhancing the ability of problem solving aspects.Identification of student mental models concerning light refraction was assessed through first interview protocol. The patterns of student response were grouped based on correct answer as scientist model.

In general the student responded that the refraction of light is a deflection of light at the interface of two media.
They stated that if the light coming perpendicularly on the interface of two media, the light was not deflected. In other words they meant that perpendicular incident light would not experience refraction.

In the second interview protocol, the students described their prediction about the part of the glass rod that will experience the effects of light refraction. The students were asked to draw a sketch of the glass rod in beaker glass filled with water. After the students describing and sketching their predictions, the interview was continued by asking them some question including: describe the sketch of the glass rod in water using ray diagram. Examples of student prediction, sketch, and the description of ray diagram were presented in Table IV.

\begin{tabular}{|l|c|c|c|}
\hline \multicolumn{1}{|c|}{ TABLE IV. } & \multicolumn{1}{c|}{$\begin{array}{c}\text { PREDICTION, SKETCh, of their } \\
\text { prediction }\end{array}$} & Ray diagram \\
\hline $\begin{array}{l}\text { deflection } \\
\text { occurs on the } \\
\text { interface of } \\
\text { two medium } \\
\text { (air- water) } \\
\text { and in water }\end{array}$
\end{tabular}

Less than $25 \%$ of the students predicted that the part of glass rod that experiences on refraction of light was the part on surface boundary of an air-water and in water with the indicator that the size of glass rod in water greater than in air. Other students predicts that the part of glass rod that experiences on refraction of light was the part on surface boundary of an air-water only.

Based on the results of the first interview and the second interview, the students were given the third interview that aimed to reflect their answers or their explanations on the first and second interview. In Table IV, it appears that the students did not understand which sections on the glass rod they were observed, so they will not understand where the light comes from. Consequently they will misrepresent their sketches into a ray diagram as shown in the figure in Table IV.

In the third interview protocol, the students were given the opportunity to change the description or sketching of the refraction of light. The last question proposed in the third interview was: Are you sure with all answers?

Based on the consistency of their answers or explanations on the first, the second, and the third interview as well as confidence in their explanation of their predictions, it was identified there were two patterns of student mental models concerning refraction. The naming of mental models for each pattern was based on the tendency of their answers or their explanations. Furthermore it was classified with theories about light refraction and wave propagation. Both mental models were identified, called as: the first ray model (by 6 students) and the second model-ray (by 10 students). 
After engaging in "ExPRession" learning model, student mental models were changed, namely: the first ray model, the second ray model, the first wave models, and the second wave model. The description of each type of students' mental model showed in Table $\mathrm{V}$ below.

TABLE V. STUDENTS MENTAL MODEL ABOUT REFRACTION

\begin{tabular}{|c|c|c|}
\hline mental model & description & $\begin{array}{c}\text { Number } \\
\text { of } \\
\text { students }\end{array}$ \\
\hline $\mathrm{n}_{1}$ & $\begin{array}{l}\text { The first ray model: } \\
\text { Students views the refraction is the } \\
\text { deflection of light on the boundaries } \\
\text { of two different medium. This } \\
\text { deflection is due to the light entering } \\
\text { from the air to another medium that } \\
\text { is denser from air density, so the } \\
\text { light will be refract close to the } \\
\text { normal }\end{array}$ & 4 \\
\hline $\mathrm{Medium}_{2}$ & $\begin{array}{l}\text { The second ray model: } \\
\text { The light bending caused by the } \\
\text { change in the speed of light in a } \\
\text { medium due to the refractive index } \\
\text { of the medium that passed different } \\
\text { light. The dense medium the smaller } \\
\text { speed of light in that medium, thus } \\
\text { light will deflected closer to the } \\
\text { normal. }\end{array}$ & 6 \\
\hline$\underbrace{\mathbf{n}_{2}}$ & $\begin{array}{l}\text { The first wave model: } \\
\text { Light is assumed as stream of } \\
\text { transverse waves. Each wave front } \\
\text { moves from one medium to the next. } \\
\text { Refraction is the change in the speed } \\
\text { of light when light enters in the } \\
\text { transparent medium of different } \\
\text { optical density. }\end{array}$ & 3 \\
\hline$\downarrow_{\text {Medium } 2}^{\text {Medimi }}$ & $\begin{array}{l}\text { The second wave model: } \\
\text { Refraction is the change of speed and } \\
\text { wavelength of light when moving } \\
\text { from a transparent medium to } \\
\text { another that different optical } \\
\text { densities. When light enters at a } \\
\text { certain angle, the direction of } \\
\text { propagation of the light will } \\
\text { refracted. }\end{array}$ & 3 \\
\hline
\end{tabular}

These changes were caused by the accustomed students engaging in activities to describe predictions and represent the problem form of diagrams, descriptions, etc. Mental models will indicate the ability in predicting solution of a problem. The changes on mental model before and after learning indicated that our learning model is effective in building mental model. Overall, the implementation of "ExPRession" learning model has an impact to increasing in problem solving ability and the establishment of student mental models, especially in the concept of light refraction.

\section{CONCLUSIONS}

Based on the result of the development model and results on limited testing, the implementation of "ExPRession" learning model could be concluded that 1) the "ExPRression" learning models can be categorized as a valid in contents (because there is an element of novelty) and as a valid in constructions (because there is consistency between parts of the developed model with learning theories), 2) the developed learning tools can be classified as a valid and could be used to support the implementation of the "Expression" learning model, 3) the "ExPRession" learning model can be categorized as "practical" because it can be executed by lecturers and students. The learning steps of "Expression" model as a form of operational planning performed well, so the "ExPRression" learning model can play as an important role in teaching the light refraction concept, mental models, and problem solving ability, 4) the "ExPRression" learning model can be categorized as an effective because it improved the problem solving ability and building student's mental model.

\section{References}

[1] Heller, P., Ketih, R., \& Anderson, S, "Teaching problem solving through cooperative group. Part 1: Group versus individual problem solving," American Journal of Physics, 60, 627-636. 1992.

[2] Reif, F. , "Teaching problem solving - A scientific approach." The Physics Teacher, 19(5), 310-316.1981.

[3] McDermott, L. "Bridging The Gap Between Teaching And Learning: The Role Of Physics Education Research In The Preparation of Teachers And Major." Investigações em Ensino de Ciências - V5(3), pp. 157-170. 2000.

[4] Hakan, Isik.. "Relationship Of College Student Characteristics And Inquirybased Geometrical Optics Instruction To Knowledge Of Image Formation With Light-Ray Tracing." Doctoral Dissertation. The Ohio State University.2008.

[5] Keawkhong, K., Narumon Emarat, Kwan Arayathanitkul, Chernchok Soankwan, Ratchapak Chitaree.. "Student's misunderstanding in using a ray diagram in light refraction." Thai Journal Of Physics, Series 3, 175. 2008

[6] Outtara, F., Barthelemie Boudaone. "Teaching and learning in geometrical optics in Burkina Faso third form classes: Presentation and analysis of class observations data and students' performance." British Journal of Science, Vol. 5(1), 83-103. 2012.

[7] Herlina, K., Mohama Nur, W. Widodo, "Identifikasi Kemampuan Problem Solving Berdasarkan Solusi Tertulis dalam Berbagai Format Representasi Problem pada Konsep Pembiasan Cahaya" Prosiding Seminar Nasional Sains, PPs UNS-Solo, 9 November 2013, pp. 626633

[8] Herlina, K., Mohama Nur, W. Widodo, "Model Mental Mahasiswa dalam Memahami Pembiasan Cahaya dan kaitannya dengan kemampuan memprediksi", Prosiding Seminar Nasional Pendidikan Sains IV-PPs Pendidikan Sains -UNS Surakarta, 15 November 2014. Pp. 118-126

[9] Merriam, S., and Caffarella, R. Learning in Adulthood: A Comprehensive Guide. San Francisco: Jossey-Bass, 1999.

[10] Prince, M. and Felder, R. "The many faces of inductive teaching and learning." Journal of College Science Teaching, Vol. 36, No. 5, 14-20. 2007.

[11] Barrows H.S. \& Tamblyn R.M. Problem-Based Learning: An Approach to Medical Education. New York: Springer Publishing Company, 1980.

[12] Hmelo-Silver, Cindy E. "Problem-Based Learning: What and How Do Students Learn?" Educational Psychology Review, Vol. 16, No. 3, September 2004. 
[13] Bridges, E. M., \& Hallinger, P. "Problem based learning in leadership education." In L. Wilkerson \& W. H. Gijselaers (Eds.), Bringing problem-based learning to higher education: Theory and practice (pp 53-61). San Francisco: Jossey-Bass. 1996.

[14] Wilkerson, L. "Tutors and small groups in problem-based learning: Lessons from the literature." In L. Wilkerson \& W. H. Gijselaers (Eds.), Bringing problem-based learning to higher education: Theory and practice. pp. 23-32). San Francisco: Jossey-Bass. 1996.

[15] Newman, M. J. "Problem Based Learning: An Introduction and Overview of the Key Features of the Approach." Journal of Veterinary Science, 12-20. 2005.

[16] Docktor, Jennifer Lynn. "Development and Validation of a Physics Problem-Solving Assessment Rubrics." Doctoral Dissertation. The Graduate School Of The University Of Minnesota. 2009. 